\title{
Chronic pericardial constriction with effusion in childhood
}

\author{
G. B. HAYCOCK AND S. C. JORDAN \\ Bristol Royal Hospital for Sick Children, and the Cardiac Department, Bristol Royal Infirmary
}

SUMMARY Five cases of children with nontuberculosis pericardial constriction with effusion are reported. The disease is not as rare as had been thought, and the aetiology in these cases was probably a previous virus infection. A previous diagnosis of hepatitis, nephrotic syndrome, or protein-losing enteropathy had been made and the correct diagnosis was delayed for months or even years. Pericardiectomy produced immediate relief from symptoms in 2 patients but in 2 others there was evidence of poor myocardial function postoperatively.

Constrictive pericarditis is rare, particularly in children. Watson (1968) estimated that: 'The disease represents not more than one in 10000 cases of cardiac disease presenting in childhood in North America at present, but it may play a larger role in other countries particularly where tuberculosis is more prevalent'. The true incidence of the disease cannot accurately be given and it may be a good deal more common than Watson thought, as it is likely that some cases are asymptomatic and others are misdiagnosed. Five cases were seen in children during a 6-year period at the Bristol Royal Hospital, where about 300 new children with cardiac disease are seen annually, an incidence of $1: 360$ such children.

\section{Case reports}

\section{Case 1.}

\section{History}

A girl, born at 38 weeks' gestation birthweight $1820 \mathrm{~g}$, was described as 'always a poor feeder from birth'. At 18 months mild lactose intolerance was diagnosed. She was referred here at 7 years with weight loss and increasing abdominal distension.

\section{Examination}

She was small and wasted (height $111 \mathrm{~cm}$, weight $18 \cdot 1 \mathrm{~kg}$ ) with conspicuous abdominal distension due to ascites and hepatomegaly. The peripheral circulation was poor, the pulse small volume with

Bristol Royal Hospital for Sick Children, Bristol

s. C. JORDAN, consultant cardiologist

Department of Paediatrics, Guy's Hospital, London

G. B. HAYCOCK, consultant paediatrician obvious reduction in volume in inspiration, 'pulsus paradoxus'. The venous pressure was raised beyond the angle of the jaw. The cardiac impulse was faint and a very loud early diastolic sound was present.

\section{Investigations}

Chest $x$-ray showed an increased cardiothoracic ratio, the heart being visible as a separate shadow within the pericardium on one overpenetrated film. The presence of an effusion was confirmed by ultrasound examination. Mantoux test negative. Viral studies, including culture of ascitic fluid, negative.

\section{Treatment}

At operation (Mr R. H. R. Belsey), both parietal and visceral pericardium were considerably thickened in a uniform fashion and a sizeable effusion was found. The parietal pericardium was removed from the major part of both ventricles, as well as most of the visceral pericardium. Histology showed thickening and fibrosis, with moderate round cell infiltration.

\section{Progress}

Although initially she required antifailure treatment, 8 months later our patient was well and the heart was clinically and radiologically normal.

\section{Case 2.}

\section{History}

A girl was transferred to this hospital for investigation of hepatomegaly and ascites. She had been born by normal delivery at term. At 6 months she was noted to have bilateral interstitial keratitis. At age 
10 months she was admitted for investigation of abdominal swelling.

\section{Examination}

Obvious ascites, enlargement of the liver and spleen. Loud early diastolic sound.

\section{Investigations}

Chest $x$-ray showed considerable cardiomegaly and the heart shape was consistent with the presence of a pericardial effusion (Fig. 1). Tuberculin test consistently negative. Viral studies negative. Abdominal paracentesis on two occasions showed straw-coloured fluid. Transpleural liver biopsy was normal histologically. Her condition deteriorated after this procedure, and she developed pulsus paradoxus; cardiac tamponade was diagnosed. Pericardiocentesis was therefore performed, $150 \mathrm{ml}$ greenish fluid being obtained, but the signs of tamponade recurred during the next 2 weeks.

\section{Operation (Mr R. H. R. Belsey)}

The heart was found to be surrounded by a densely adherent, grossly thickened visceral pericardium which was severely impeding cardiac filling. The parietal pericardium was thickened also, and was removed in its entirety, large portions of the visceral pericardium being dissected off the ventricles and

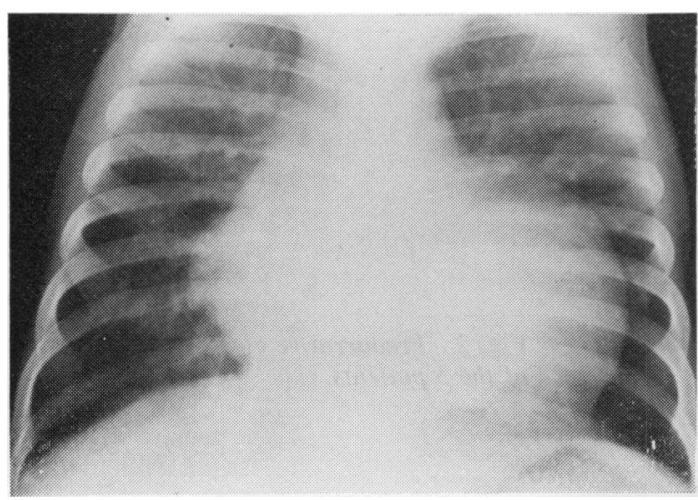

Fig. 1 Case $2 x$-ray. Cardiac shadow is enlarged but a faint medial opacity due to the heart itself is also shown. removed also. Histologically the excised tissue showed dense fibrosis with scanty chronic inflammatory cells.

\section{Progress}

During the next 7 days large volumes of fluid drained from the left chest drain, but this gradually tailed off and thereafter her postoperative recovery was rapid and uneventful with prompt disappearance of all signs of impaired right heart filling. Five years later she remains perfectly well and the cardiovascular system appears normal.

\section{Case 3.}

\section{History}

A girl was noted at age 2 years to be breathless and cyanosed on exertion. Medical advice was not sought at that time and she presented at age 8 years with effort dyspnoea and occasional right-sided chest pain on exertion.

\section{Examination}

Slight central cyanosis. Small volume pulses. Jugular venous pressure greatly raised, with prominent $\mathrm{A}$ - and V-waves. No abnormalities were detected on auscultation. Liver palpable $3 \mathrm{~cm}$ below the right costal margin.

\section{Investigations}

Chest $x$-ray showed gross cardiomegaly with prominence of the superior vena cava and of the veins of the upper lobes of the lungs. Multiple opacities and septal lines were present at the bases, with a small right-sided pleural effusion. Tuberculin test negative. Antibodies to $\mathbf{Q}$ fever, psittacosis, Mycoplasma, mumps, and Toxoplasma gondii negative. Viral culture in HeLa and monkey kidney cells negative. Cardiac catheterisation (Table).

\section{Operation}

A pericardiectomy was performed (Mr G. Keen). The pericardium looked thickened and there was a moderate accumulation of pericardial fluid. Histologically the pericardium was moderately thickened but it was otherwise normal.

Table Cardiac catheterisation

\begin{tabular}{|c|c|c|c|c|c|c|c|c|c|}
\hline \multirow[t]{3}{*}{ Case } & \multicolumn{2}{|c|}{ Right atrium $(\mathrm{mmHg})$} & \multirow{3}{*}{$\begin{array}{l}\text { Right ventricle } \\
(\mathrm{mm} H \mathrm{Hg})\end{array}$} & \multicolumn{2}{|c|}{ Pulmonary artery $(\mathrm{mmHg})$} & \multirow{3}{*}{$\frac{\begin{array}{l}\text { Wedge } \\
(\mathrm{mmHg})\end{array}}{\text { Mean }}$} & \multirow{3}{*}{$\begin{array}{l}\text { Left ventricle } \\
(\mathrm{mmHg})\end{array}$} & \multicolumn{2}{|c|}{$A-\mathrm{O}_{2}$ difference } \\
\hline & \multirow[t]{2}{*}{ A-wave } & \multirow[t]{2}{*}{ Mean } & & \multirow[t]{2}{*}{$S / D$} & \multirow[t]{2}{*}{ Mean } & & & \multirow[t]{2}{*}{$\%$} & \multirow[t]{2}{*}{$\mathrm{O}_{2}$ content } \\
\hline & & & & & & & & & \\
\hline 3 & 36 & 28 & $100 / 12 / 25$ & $100 / 65$ & 80 & 26 & $100 / 12 / 25$ & 54 & $9 \cdot 6$ \\
\hline 4 & 9 & 8 & $35 / 6 / 8$ & $33 / 12$ & 18 & 12 & - & - & 一 \\
\hline 5 & 30 & 25 & $42 / 15 / 25$ & $40 / 30$ & 32 & 26 & 一 & 39 & $6 \cdot 3$ \\
\hline
\end{tabular}




\section{Progress}

Jugular venous pressure fell almost to normal and she was symptomatically greatly improved, but continued to show mild cardiomegaly and abnormal $\mathrm{T}$-waves in the ECG. She died suddenly 2 years later, presumably from an arrhythmia.

\section{Case 4.}

\section{History}

A girl born by normal delivery at 38 weeks' gestation, birthweight $3200 \mathrm{~g}$. She was admitted to hospital at age 2 months for investigation of convulsions. A chest $x$-ray showed a cardiothoracic ratio of $0 \cdot 6$, and an ultrasound cardiogram showed a moderate sized pericardial effusion and a small or normal sized heart.

\section{Progress}

Radiological signs of pericardial effusion remained for 2 years but then gradually subsided and our patient has since remained well.

\section{Case 5.}

\section{History}

A $2 \frac{1}{2}$-year-old girl was referred to this hospital with a one-year history of lethargy, oedema, and abdominal swelling. She was seen at another hospital and found to have albuminuria, and a tentative diagnosis of nephrotic syndrome was made; later this was changed to active hepatitis and then to protein-losing enteropathy.

\section{Examination}

Oedema of legs and face and moderate ascites. Liver $10 \mathrm{~cm}$ below the costal margin, jugular veins engorged with no obvious pulsation. A loud, early diastolic sound was audible all over the praecordium.

\section{Investigations}

Chest $x$-rays showed an enlarged cardiac shadow. ECG showed right and left atrial hypertrophy, small voltage QRS complexes, and flat T-waves (Fig. 2). Cardiac catheterisation (Table) showed findings

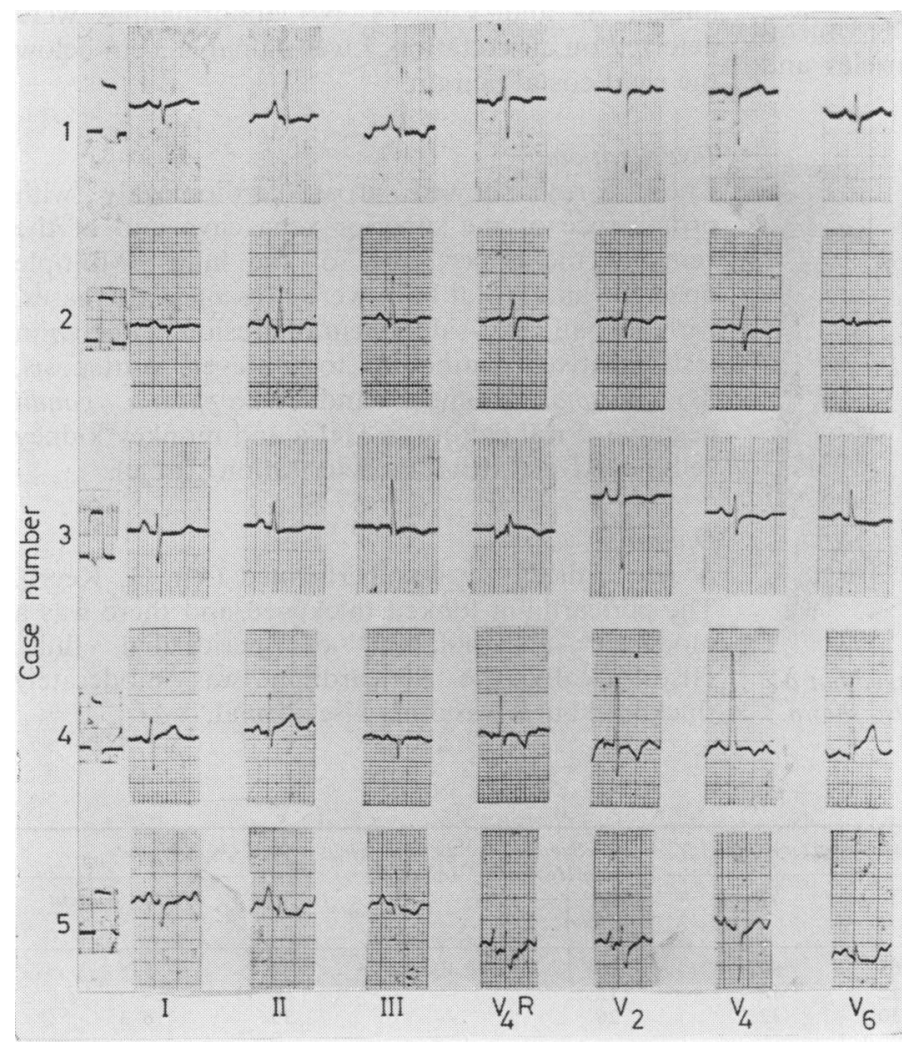

Fig. 2 Preoperative electrocardiograms of the 5 patients. 
consistent with pericardial constriction, there being a pronounced 'dip and plateau' pattern in the right ventricular trace.

Operation (Mr R. H. R. Belsey)

The parietal pericardium was mildly thickened and distended by a large straw-coloured effusion. There was no adhesion of visceral and parietal pericardium. The pericardium was excised between the phrenic nerves. It was uniformly thickened with moderate numbers of chronic inflammatory cells.

\section{Progress}

Postoperatively the patient continued to drain moderate quantities of fluid for 7 days ( $1 \cdot 6$ litres) through the left pleural drain. After removal of the drain, fluid reaccumulated in the left chest and a further $2 \cdot 8$ litres were removed, by repeated paracentesis, but eventually the effusion was controlled by frusenide $20 \mathrm{mg}$ daily. During the next 6 weeks the dose was reduced and she remained well with a normal venous pressure and no abnormal signs. Four months after operation the venous pressure was again raised. The cardiac size on $x$-ray was within normal limits. Repeat cardiac catheterisation still showed equally raised right atrial and pulmonary wedge pressures. The chest was re-explored to exclude recurrent constriction but none was found. Six months later she still required a moderate dose of diuretic $(10 \mathrm{mg}$ frusemide daily) to keep her out of failure, and this has continued to do so to date.

\section{Discussion}

Aetiology. The 5 cases described have in common the presence of persistent pericardial effusion. This was associated with impaired heart filling in 4 and proved thickening of the pericardium in 3 . The aetiology is obscure in all, although in 2 of the children there were associated features which support the suggestion of viral infection. Presumptive evidence for a virus aetiology to explain 'idiopathic' pericardial constriction was produced by Robertson and Arnold (1962) who found a cluster of about 5 such cases a year after an epidemic of virus pericarditis: 2 of their patients had had pericarditis during the epidemic (caused by Coxsackie B5 virus). In our Case 2 the coexistence of interstitial keratitis with negative serology for syphilis, and in Case 1 the low birthweight for gestational age and poor progress from birth, would be consistent with this possibility.

It was usually assumed, before the introduction of effective antituberculous chemotherapy, that tuberculosis accounted for most of the cases diagnosed as constrictive pericarditis. Simcha and Taylor (1971) stated: 'Tuberculosis plays a major role in the aetiology of constrictive pericarditis; strong evidence of this is found in this series'. This claim seems difficult to justify on the basis of their paper since in only one of 5 cases was a diagnosis of tuberculosis well established, and the evidence adduced in favour of this disease in 2 other cases was not convincing. Indeed, some doubt existed about the importance of tuberculosis as the main cause of constrictive pericarditis even before the introduction of streptomycin; of 37 cases (all children) reviewed by Rothstein (1934) tuberculosis was given as the diagnosis in only 9 , with one doubtful, the remainder being attributed to rheumatism or 'unknown' in roughly equal proportions. Other authors (Mortensen and Warburg, 1948; Kuipers, 1955; Vining, 1955; Dalton et al., 1956; Shea et al., 1957; Caddell et al., 1960) have presented small series of children, or included the occasional child in series of adults, but in these papers tuberculosis did not feature prominently as a proved cause. Even in countries where tuberculosis is common it probably only accounts for about half the number of cases (Das et al., 1973).

Apart from tuberculosis, a variety of other disease processes have occasionally been found to cause constrictive pericarditis; these include histoplasmosis, Coxsackie pericarditis (particularly strains B3 and B5), traumatic haemopericardium, rheumatoid disease, hydatid disease, myxoedema, amyloidosis, sepsis (for example meningococcal and staphylococcal septicaemia), and malignant disease. Practically all accounts agree, however, that in any sizeable series the majority of cases occur in the absence of any identifiable primary disease, and the known causes, even collectively, constitute the minority (British Medical Journal, 1968; Keith et al., 1968; Watson, 1968; Mullen et al., 1969).

The role of acute rheumatism, if any, in the aetiology of constrictive pericarditis is not clear. Simcha and Taylor (1971) regarded it as hardly ever leading to constrictive pericarditis, while Rothstein (1934) attributed 13 of 37 cases to this cause.

Our 5 cases had moderately large, serous effusions, separating parietal and visceral pericardium. This is not generally a feature of tuberculous constrictive pericarditis, but is in keeping with the findings of Harrold (1968) in 3 adults with nontuberculous pericardial constriction. Cayler et al. (1963) found moderately large pericardial effusions in their patients, but each one presented during the course of acute pericarditis.

Diagnosis. Although 2 of our patients presented with short histories and the diagnosis was suspected before referral, the other 3 were clearly undiagnosed 
for periods of several months or years. The failure to diagnose the presence of pericardial constriction was partly due to failure to notice or realise the significance of the raised venous pressure. If the venous pressure is so high that there is no longer obvious venous pulsation in the neck, the difficulties of assessment are well known. Another factor in the failure to make a diagnosis was the presence of secondary effects of the high venous pressure. Hepatic enlargement with abnormal liver function tests led to a diagnosis of active hepatitis and liver biopsy was performed (a procedure not without risk when the venous pressure is high). Similarly the effect of high venous pressure in the kidneys may cause a secondary nephrotic syndrome. Our Case 5 was similar in this respect to a 58-year-old patient reported by Pastor and Cahn (1960). Case 5 was initially diagnosed as having protein-losing enteropathy and this too has been reported as a complication of pericardial constriction (Plauth et al., 1964).

The auscultatory signs in pericardial constriction are not obvious. Three of our patients had a loud, early diastolic sound, but this is often so early that it is mistaken for the second sound. The ECG is not specific and patients with only a small effusion, or none, may have a remarkably normal looking cardiac size and shape on chest $x$-rays. Diagnostic ultrasound (Feigenbaum et al., 1967) is useful when there is a pericardial effusion.

Treatment. There were clear indications in 4 of our patients for surgical treatment. In one of them treatment was required fairly urgently for rapidly increasing signs of right heart failure and reduced cardiac output. In the other 3 there were obvious indications from the secondary effects of high venous pressure on the liver, kidneys, and gut. The surgeon's aim is to remove the thickened pericardium (visceral as well as parietal if necessary) from more than half the surface of the heart so that any further contraction of the remaining pericardium does not constrict the heart. In 2 of the operated patients the pericardial effusion separated parietal and visceral pericardium. In the other 2 a variable amount of dissection of pericardium from the heart itself was necessary. The exudative nature of the pericarditis is well shown by the 2 patients (Cases 2 and 5) who continued to drain fluid for several days or weeks after pericardiectomy. This was a surprising feature in view of the almost complete lack of signs of inflammation microscopically in the excised pericardium.

Myocardial involvement. Two of our patients (Cases 3 and 5) probably had chronic myocardial damage and Case 1 also showed temporary cardiac failure in the postoperative period. The possible reasons for myocardial involvement were reviewed by Levine (1973). Possible explanations are associated myocardial fibrosis (particularly if a viral aetiology is suspected), and the splinting effect of the constriction preventing the heart from dilating adequately.

We thank Dr J. A. Apley for permission to report Cases 1, 2, and 4 and Dr F. G. M. Ross for carrying out ultrasound cardiograms in Cases 1, 2, 4, and 5.

\section{References}

British Medical Journal (1968). Editorial: Non-tuberculous constrictive pericarditis. British Medical Journal, 1, 265-266.

Caddell, J. L., Friedman, S., and Johnson, J. (1960). Constrictive pericarditis. American Journal of Diseases of Children, 100, 850-856.

Cayler, G. G., Taybi, H., Riley, H. D., Jr, and Simon, J. L. (1963). Pericarditis with effusion in infants and children. Journal of Pediatrics, 63, 264-272.

Dalton, J. C., Pearson, R. J., Jr, and White, P. D. (1956). Constrictive pericarditis: a review and long term follow up of 78 cases. Annals of Internal Medicine, 45, 445-458.

Das, P. B., Gupta, R. P., Sukumar, I. P., Cherian, G., and John, S. (1973). Pericardiectomy: indication and results. Journal of Thoracic and Cardiovascular Surgery, 66, 58-70.

Feigenbaum, H., Zacky, A., and Waldhausen, J. A. (1967). Use of reflected ultrasound in detecting pericardial effusion. American Journal of Cardiology, 19, 84-90.

Harrold, B. P. (1968). Non-tuberculous constrictive pericarditis. British Medical Journal, 1, 290-292.

Keith, J. D., Rowe, R. D., and Vlad, P. (1968). In Heart Disease in Infancy and Childhood, second edition, p. 987. Macmillan: New York.

Kuipers, F. (1955). Chronic constrictive pericarditis combined with hypoproteinaemia. Archives of Disease in Childhood, 30, 285-292.

Levine, H. D. (1973). Myocardial fibrosis in constrictive pericarditis. Electrocardiographical and pathologic observations. Circulation, 48, 1268-1281.

Mortensen, V., and Warburg, E. (1948). Chronic constrictive pericarditis. Acta medica Scandinavica, 131, 203-225.

Mullen, D. C., Dillon, M. L., Young, W. G., Jr, and Sealy, W. C. (1969). Pericardiectomy in non-tuberculous pericarditis. Journal of Thoracic and Cardiovascular Surgery, 58, 517-529.

Pastor, B. H., and Cahn, M. (1960). Reversible nephrotic syndrome resulting from constrictive pericarditis. New England Journal of Medicine, 262, 872-874.

Plauth, W. H., Jr, Waldmann, T. A., Wochner, R. D., Braunwald, N. S., and Braunwald, E. (1964). Proteinlosing enteropathy secondary to constrictive pericarditis in childhood. Pediatrics, 34, 636-648.

Robertson, R., and Arnold, C. R. (1962). Constrictive pericarditis with particular reference to etiology. Circulation, 26, 525-529.

Rothstein, J. L. (1934). Chronic adhesive pericarditis in children and its surgical treatment. II Report of a case of Pick's disease in a 12 year old child; abstracts from the literature of cases operated on, with an analysis of results; conclusions. Archives of Pediatrics, 51, 288-309. 
Shea, D. W., Kirklin, J. W., and DuShane, J. W. (1957). Chronic constrictive pericarditis in children. American Journal of Diseases of Children, 93, 430-435.

Simcha, A., and Taylor, J. F. N. (1971). Constrictive pericarditis in childhood. Archives of Disease in Childhood, 46, 515-519.

Vining, C. W. (1955). Constrictive pericarditis in early childhood (abstract). Proceedings of the Royal Society of Medicine, 48, 1105.

\section{Change of reference style}

From January 1980, the Archives will change its style for citing references and will follow the number system. We are making this change in order to conform with the 'Vancouver style' of uniform requirements for manuscripts submitted to biomedical journals.

Previously the Archives has used the Harvard reference system. Its advantages and disadvantages compared with those of the number system have seemed evenly balanced, but the editors have been aware of the burden imposed on authors and their secretaries by the different styles which different journals require. Therefore, with the unanimous agreement of the editorial committee, we have decided to support a move whereby a large-and increasing-number of major medical journals
Watson, H. (1968). In Paediatric Cardiology, p. 723. LloydLuke: London.

Correspondence to Dr S. C. Jordan, Bristol Royal Hospital for Sick Children, Cardiology Department, St Michael's Hill, Bristol BS2 8BJ.

Received 29 February 1979

will accept manuscripts presented in one agreed style.

The system numbers references consecutively in the order in which they are first mentioned in the text. References are identified in the text by arabic numerals. For further details see instructions to authors inside the front cover, and the references cited. ${ }^{1,2}$

From now onwards all manuscripts submitted should accord with the new style.

1 International Steering Committee of Medical Editors. Uniform requirements for manuscripts submitted to biomedical journals. Br Med J 1979; 1 : 533-535.

2 Lancet. The Vancoiver style. Uniform requirements for manuscripts submitted to biomedical journals. Lancet $1979 ; 1$ : 429-430. 